\title{
Stimulated thyroglobulin level at ablation in differentiated thyroid cancer: the impact of treatment preparation modalities and tumor burden
}

\author{
Renaud Ciappuccini ${ }^{1}$, Juliette Hardouin ${ }^{1,2}$, Natacha Heutte ${ }^{3}$, Dominique Vaur ${ }^{4}$, \\ Elske Quak ${ }^{1}$, Jean-Pierre Rame ${ }^{5}$, David Blanchard ${ }^{5}$, Dominique de Raucourt ${ }^{5}$ and \\ Stéphane Bardet ${ }^{1}$ \\ ${ }^{1}$ Departments of Nuclear Medicine and Thyroid Unit, Centre François Baclesse, 3 Avenue Général Harris, BP 5026, \\ F-14076 Caen Cedex 05, France, ${ }^{2}$ Department of Endocrinology, Centre Hospitalo-Universitaire, Caen, France, \\ ${ }^{3}$ U1086 INSERM-UCBN Cancers et Préventions, Caen, France, Departments of ${ }^{4}$ Biology and ${ }^{5} \mathrm{Head}$ and Neck Surgery, \\ Centre François Baclesse, Caen, France
}

Correspondence
should be addressed
to R Ciappuccini
Email
r.ciappuccini@baclesse.fr

\begin{abstract}
Objective: In patients with differentiated thyroid cancer (DTC), the stimulated serum thyroglobulin (Tg) level at radioiodine ablation is a known predictive factor of persistent disease. This prognostic value is based on data obtained after thyroid hormone withdrawal (THW), but little is known about this prognostic value after recombinant human TSH (rhTSH) stimulation and about the relationship between the stimulated Tg level and the burden of persistent tumor. We aimed to assess the impact of both radioiodine preparation modalities and persistent tumor burden on stimulated Tg levels.

Design and methods: The stimulated Tg level was measured at radioablation in 308 consecutive DTC patients without serum Tg antibodies. Of these, 123 (40\%) were prepared with rhTSH and 185 with THW. Post-ablation scintigraphy included total-body scan and neck and thorax single photon emission computed tomography with computed tomography (SPECT-CT). During a mean follow-up of 43 months, persistent/recurrent disease (PRD) was found in 56 patients (18\%). PRD was considered structural in the presence of lesions $>1 \mathrm{~cm}$ and nonstructural otherwise.

Results: Nonstructural PRD was more frequent in the rhTSH group than in the THW group (64 vs $26 \%, P=0.01)$. Stimulated Tg levels were lower after rhTSH than after THW in patients with ( $13.5 \mathrm{vs} 99.5 \mathrm{ng} / \mathrm{ml}, P<0.01)$ and without $(1.2 \mathrm{vs} 3.2 \mathrm{ng} / \mathrm{ml}, P<0.001)$ PRD. Also, Tg levels were lower in nonstructural disease than in structural disease in both rhTSH $(3.8 \mathrm{vs} 127.0 \mathrm{ng} / \mathrm{ml}, P<0.01)$ and THW (13.0 vs $143.5 \mathrm{ng} / \mathrm{ml}, P<0.0001$ ) patients. The best Tg cutoff to predict PRD was $2.8 \mathrm{in} \mathrm{rhTSH}$ and $28 \mathrm{ng} / \mathrm{ml}$ in THW patients. Conclusion: Both radioiodine preparation modalities and the burden of persistent tumor affect the stimulated Tg level
\end{abstract} at ablation.

\section{Introduction}

In patients with differentiated thyroid cancer (DTC), the stimulated serum thyroglobulin (Tg) level measured at radioiodine ablation has a good prognostic value for persistent/recurrent disease (PRD). A low Tg level has a high negative predictive value (NPV) (1), whereas a high Tg level is frequently associated with persistent disease $(2,3)$. Several factors including the thyroid-stimulating hormone (TSH) stimulation modalities (4), the burden of residual tumor disease, and the volume of the thyroid remnants potentially influence the stimulated serum $\mathrm{Tg}$ level. Stimulated Tg level cutoffs have been mainly established after thyroid hormone withdrawal (THW) $(2,5)$, whereas data on stimulated Tg level after recombinant human TSH (rhTSH) stimulation are very limited (6).
ㄷ 2014 European Society of Endocrinology Printed in Great Britain
European Journal of Endocrinology

(2014) 171, 247-252 
As rhTSH has recently emerged as the most widely used method for radioiodine ablation preparation, especially in low-risk patients $(7,8)$, there is a need to assess the $\mathrm{Tg}$ response after rhTSH and to compare it with that obtained after THW. The production of Tg by well-differentiated tumor cells generally correlates with the tumor burden. Little is known, however, about the influence of the volume of residual disease on the stimulated Tg-level after rhTSH or THW preparation.

We aimed to assess the impact of both radioiodine preparation modalities and persistent tumor burden on stimulated Tg levels and to correlate these data with patients' outcomes.

\section{Materials and methods}

\section{Patients}

The records of 363 consecutive patients with DTC who were referred to our institution for radioiodine ablation between January 2006 and January 2012 were reviewed. Fifty-five patients (15\%) with Tg antibodies (TgAb) were excluded from the data analysis. The study group thus included 308 patients.

\section{Radioiodine ablation and preparation modalities}

Radioiodine ablation was administered after either THW or rhTSH. In patients who were given levothyroxine $\left(\mathrm{L}-\mathrm{T}_{4}\right)$ after surgery, THW consisted of stopping $\mathrm{L}^{-\mathrm{T}_{4}} 35$ days before the radioiodine treatment and replacing it with levotriiodothyronine ( $\left.\mathrm{L}-\mathrm{T}_{3}\right)$ during the first 23 days. In patients who were given $\mathrm{L}_{-} \mathrm{T}_{3}$ after surgery, $\mathrm{L}-\mathrm{T}_{3}$ was withdrawn 12 days before the radioiodine treatment. The rhTSH stimulation consisted of two i.m. injections of $0.9 \mathrm{mg}$ of rhTSH (Thyrogen, Genzyme Corp., Cambridge, MA, USA), one on each of the 2 days before the radioiodine treatment. In all patients, the TSH level was above $30 \mathrm{mUI} / 1$ on the day of radioiodine treatment. The radioiodine activity (1.1 or 3.7 GBq) and the preparation modalities were determined at the local multidisciplinary thyroid meeting, except for the 42 low-risk patients enrolled in the ESTIMABL trial (7). A post-ablation ${ }^{131}$ I total-body scan with neck and thorax SPECT-CT was performed 2 or 5 days following 1.1 or 3.7 GBq, respectively, as previously described (9).

\section{Tg assay}

For stimulated serum Tg measurements, blood samples were collected immediately before the radioiodine treatment and stored at $-20^{\circ} \mathrm{C}$. For the purpose of this study, all serum Tg levels were measured using Roche Cobas $6000 \mathrm{Tg}$ (Roche Diagnostics) with a lower detection limit of $0.1 \mathrm{ng} / \mathrm{ml}$ and a functional sensitivity of $1.0 \mathrm{ng} / \mathrm{ml}$.

\section{Definition of PRD}

PRD was defined as evidence of tumor in the thyroid bed, lymph-node metastases, or distant metastases after completion of the initial treatment (surgery and radioiodine ablation), that is from ablation to last follow-up visit. Confirmation was obtained either by histology or by complementary imaging modalities and follow-up. Otherwise, patients were considered disease free.

In an attempt to assess the tumor burden, PRD was classified into two categories, that is structural or nonstructural lesions. Structural disease was defined by large $(>1 \mathrm{~cm})$ lesions, clearly evidenced by conventional radiology, disregarding the presence or absence of scintigraphic abnormalities. Conversely, nonstructural disease was defined either by the presence of clearly abnormal foci on post-ablative radioiodine scintigraphy or identified on 18-Fluorodeoxyglucose- positron emission tomography (FDG-PET) scan without obvious lesions on conventional modalities (neck ultrasound (US), CT scan, and magnetic resonance imaging), or small-volume $(<1 \mathrm{~cm})$ radiological lesions, whatever their scintigraphic profile.

\section{Clinical outcome assessment}

As previously described (9), patients with a normal postablation ${ }^{131}$ I scan were observed at 3 months by serum $\mathrm{TSH}, \mathrm{Tg}$, and $\mathrm{TgAb}$ assays on $\mathrm{L}^{-} \mathrm{T}_{4}$ treatment. When the $\mathrm{Tg}$ level was $<1 \mathrm{ng} / \mathrm{ml}$ in the absence of $\mathrm{TgAb}$, the disease status was assessed at 9 months by serum rhTSHstimulated Tg assay and neck US. When the evaluation at 9 months was normal (i.e. stimulated-Tg level $\leq 1 \mathrm{ng} / \mathrm{ml}$ and normal US), patients were followed up on an annual basis. Otherwise, imaging modalities such as CT of the neck and thorax or FDG-PET scan were performed.

\section{Statistical analysis}

Patients' characteristics were compared using Fisher's exact test, the Wilcoxon's test, or the Kruskal-Wallis test, as appropriate. Sensitivity, specificity, positive predictive value (PPV), and NPV are presented with exact CIs. Statistical significance was defined as $P<0.05$. All tests were two-sided. SAS 9.3 Statistical Software (SAS Institute, Inc., Cary, NC, USA) was used to analyze the data. 
Table 1 Characteristics of patients.

\begin{tabular}{|c|c|c|c|}
\hline & rhTSH $(n=123)$ & THW $(n=185)$ & $P$ value \\
\hline Women & $102(83 \%)$ & $124(67 \%)$ & $<0.01$ \\
\hline Age (years) & $51 \pm 16$ & $49 \pm 18$ & 0.12 \\
\hline \multicolumn{4}{|c|}{$\begin{array}{l}\text { TNM classification, } \\
\text { 7th edn }\end{array}$} \\
\hline T status & & & $<0.0001$ \\
\hline $\mathrm{T} 1 \mathrm{a}+\mathrm{T} 1 \mathrm{~b}$ & $44+38(66 \%)$ & $30+41(38 \%)$ & \\
\hline T2 & $25(21 \%)$ & $61(33 \%)$ & \\
\hline T3 & $15(12 \%)$ & $47(26 \%)$ & \\
\hline T4a & $1(1 \%)$ & $6(3 \%)$ & \\
\hline $\mathrm{N}$ status & & & $<0.0001$ \\
\hline $\mathrm{Nx}$ & $75(61 \%)$ & $71(38 \%)$ & \\
\hline NO & $35(28 \%)$ & $46(25 \%)$ & \\
\hline $\mathrm{N} 1 \mathrm{a}+\mathrm{N} 1 \mathrm{~b}$ & $11+2(11 \%)$ & $36+32(37 \%)$ & \\
\hline M status ${ }^{a}$ & & & 0.02 \\
\hline M0 & 119 (97\%) & $166(90 \%)$ & \\
\hline M1 & $4(3 \%)$ & $19(10 \%)$ & \\
\hline Pathology & & & 0.03 \\
\hline PTC & $112(90 \%)$ & $154(83 \%)$ & \\
\hline FTC & $11(10 \%)$ & $23(13 \%)$ & \\
\hline PDTC & 0 & $8(4 \%)$ & \\
\hline
\end{tabular}

PTC, papillary thyroid cancer; FTC, follicular thyroid cancer; PDTC, poorly differentiated thyroid cancer.

${ }^{\mathrm{a}} \mathrm{M}$ status determined after post-ablation radioiodine scintigraphy.

\section{Results}

\section{Characteristics of patients}

Patients' characteristics are summarized in Table 1 . The study group included 266 papillary thyroid cancers, 34 follicular thyroid cancers, and eight poorly DTC. There were 226 women (73\%) and 82 men. The mean age was $50 \pm 17$ years.

For radioiodine ablation, 123 patients (40\%) were prepared with rhTSH and 185 patients (60\%) with THW. The rhTSH group included a higher proportion of T1 tumors (66 vs $38 \%, P<0.0001$ ), a lower proportion of N1 patients (11 vs $37 \%, P<0.0001$ ), and a lower proportion of M1 patients ( 3 vs 10\%, $P=0.02$ ). The rhTSH and THW groups also differed for sex $(P<0.01)$ and pathology $(P=0.03)$ (Table 1$)$.

The mean follow-up period was 43 months. PRD was found in 56 patients, including 29 with nodal disease, 16 with distant metastases (lung, 10; bone, 4; and both, 2), six with both nodal and distant metastases, and five with residual tumor in the thyroid bed (including one with lung and one with bone metastases). Of these 56 patients, 42 had been prepared using THW and 14 using rhTSH stimulation. Twenty of the 56 patients with PRD were considered to have nonstructural lesions and 36 to have structural lesions. Nonstructural PRD was more frequent in the rhTSH group than in the THW group (nine out of $14,64 \%$ vs 11 out of $42,26 \%, P=0.01$ ).

\section{Stimulated serum $\mathrm{Tg}$ values at ablation}

The median stimulated $\mathrm{Tg}$ value was lower after rhTSH than after THW in patients who remained disease free (1.2 $(0.1-209)$ vs $3.2(0.1-88) \mathrm{ng} / \mathrm{ml}, P<0.001)$ and in those who presented PRD (13.5 (1.1-439) vs 99.5 (6.3-58 690) $\mathrm{ng} / \mathrm{ml}, P<0.01$ ).

The stimulated $\mathrm{Tg}$ value at ablation was also lower in patients without PRD than in patients with nonstructural disease in both the rhTSH group (1.2 (0.1-209) vs $3.8(1.1-55) \mathrm{ng} / \mathrm{ml}, P<0.03)$ and the THW group (3.2 $(0.1-88)$ vs $13.0(6.3-117) \mathrm{ng} / \mathrm{ml}, P=0.0001)$. Moreover, the stimulated $\mathrm{Tg}$ value was lower in patients with nonstructural than structural PRD after both rhTSH (3.8 (1.1-55) vs $127.0(31-439) \mathrm{ng} / \mathrm{ml}, P<0.01)$ and THW $(13.0(6.3-117)$ vs 143.5 (16.1-58 690) ng/ml, $P<0.0001$ ) (Fig. 1).

In the group of patients with nonstructural PRD, stimulated Tg levels were lower in rhTSH patients than that in THW patients (3.8 (1.1-55) vs 13.0 (6.3-117) $\mathrm{ng} / \mathrm{ml}, P<0.03$; Fig. 1$)$. No such statistical difference was observed in the structural group (127.0 (31-439) vs 143.5 (16.1-58 690) $\mathrm{ng} / \mathrm{ml}, P=0.31$ ).

\section{Receiver operating characteristics analysis}

In the THW patients, the receiver operating characteristics (ROC) study showed that the optimal cutoff for the

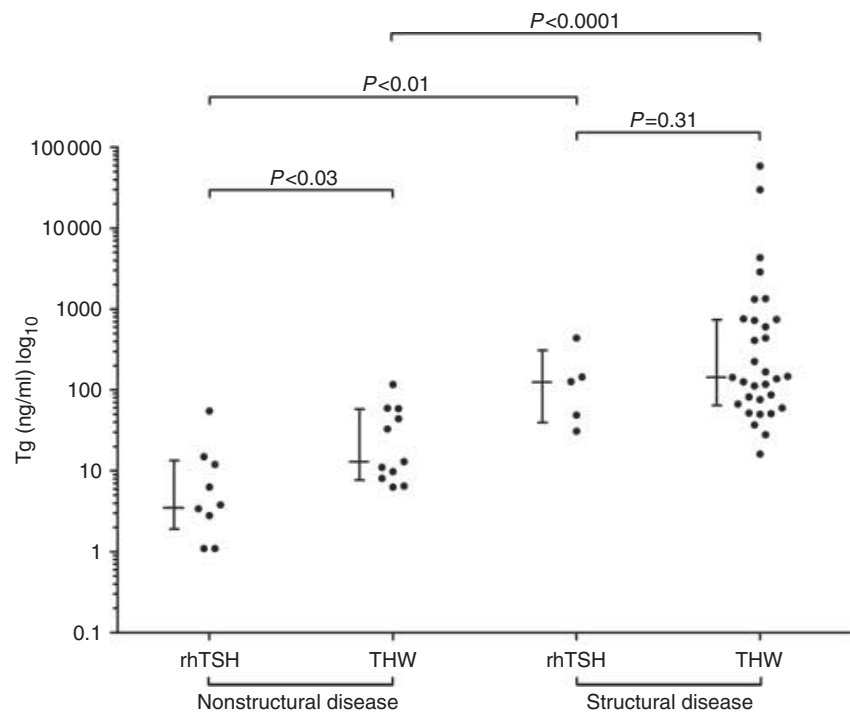

Figure 1

Stimulated serum thyroglobulin $(\mathrm{Tg})$ levels at ablation according to tumor burden (nonstructural or structural persistent/recurrent disease) and preparation modality (rhTSH stimulation or thyroid hormone withdrawal (THW)). 
stimulated serum Tg level to predict PRD was $28 \mathrm{ng} / \mathrm{ml}$. This cutoff yielded sensitivity of $83 \%$ (95\% CI, 68-93\%), specificity of $94 \%$ (95\% CI, 88-97\%), PPV of $80 \%$ (95\% CI, 65-91\%), and NPV of 95\% (95\% CI, 90-98\%). Similarly, the optimal cutoff in the rhTSH patients was found to be ten times lower at $2.8 \mathrm{ng} / \mathrm{ml}$ with sensitivity of $86 \%$ (95\% CI, 57-98\%), specificity of 64\% (95\% CI, 55-73\%), PPV of $24 \%$ (95\% CI, 13-37\%), and NPV of 97\% (95\% CI, 90-100\%).

\section{Discussion}

The present data show the impact of both the treatment preparation modalities and the tumor burden on the stimulated serum Tg level measured at radioiodine ablation. These results were obtained in 308 consecutive nonselected DTC patients using the same Tg assay, all of whom had been treated in the same way with surgery and radioiodine ablation, and all of whom had undergone sensitive post-ablation scintigraphy combining total-body scan and neck and thorax SPECT-CT.

In France, rhTSH has been commercially available for radioablation since 2005 , first with authorization limited to low-risk DTC patients, and since 2010, to all DTC patients except those with known distant metastases. Therefore, most radioiodine treatments are now administered after rhTSH and the assessment of stimulated Tg after this preparation has become mandatory. Until now, studies on the stimulated serum Tg level at ablation have been performed almost exclusively in patients prepared with THW $(2,3,5,10,11,12)$. We found lower stimulated Tg levels in patients prepared with rhTSH than in those prepared with THW (4). There were few data regarding stimulated Tg levels in the two recent randomized trials that compared low- and high-dose radioiodine after THW or rhTSH $(7,8)$. In the ESTIMABL study, which included low-risk patients of whom more than 90\% achieved complete ablation, the proportion of patients with a Tg level $\leq 1 \mathrm{ng} / \mathrm{ml}$ was higher in patients prepared with rhTSH (59\%) than in those prepared with THW (38\%) (7). Such a difference was not reported in the HILO trial, in which the proportion of patients with a Tg level $<2 \mathrm{ng} / \mathrm{ml}$ was $25 \%$ in both the rhTSH and THW groups (8). Nevertheless, specific data on stimulated Tg levels in patients who showed or did not show PRD were not reported in either study.

Several factors may account for lower stimulated $\mathrm{Tg}$ levels in patients prepared with rhTSH than in those prepared with THW. First, rhTSH stimulates less Tg production than does THW (4). This was demonstrated in the patients of our study who never showed PRD and in whom the Tg level was exclusively related to normal thyroid remnants. Second, stimulated Tg was measured 2 days after the first rhTSH injection, immediately before the radioiodine treatment, thus resulting in lower $\mathrm{Tg}$ values than those expected at 4 days $(13,14)$. The main advantage of assessing rhTSH-stimulated Tg before radioiodine ablation is to overcome the serum Tg increase due to the effects of radiation on thyroid remnants (15). Third, the present data strongly suggest that the stimulated Tg level is related to the burden of PRD. Indeed, we consistently found lower $\mathrm{Tg}$ values in nonstructural (microscopic) than that in structural (macroscopic) residual disease, whatever the radioiodine preparation modality used. The lower stimulated Tg value in the rhTSH group than that in the THW group was also related to a higher proportion of nonstructural PRD in the rhTSH subgroup, which was probably the consequence of a selection bias due to regulations concerning the use of rhTSH between 2006 and 2012. Patients prepared with rhTSH had better prognostic characteristics than those prepared with THW. A correlation between tumor burden and stimulated Tg levels after THW had already been reported in patients with lymph node disease (16).

In previous studies, reported Tg cutoffs for predicting PRD after THW were highly variable, ranging from 10 to $58 \mathrm{ng} / \mathrm{ml}$ depending on the Tg assay used, on the TNM status of the patients studied, on the methods used to determine the $\mathrm{Tg}$ threshold (ROC analysis or selection of an empirical cutoff), and on the methods used to detect PRD. We found a Tg cutoff of $28 \mathrm{ng} / \mathrm{ml}$ in the THW group and a ten times lower Tg cutoff of $2.8 \mathrm{ng} / \mathrm{ml}$ in the $\mathrm{rhTSH}$ group. In a recent meta-analysis involving 3947 patients, Webb et al. (1) found that a $10 \mathrm{ng} / \mathrm{ml}$ cutoff after THW was associated with the optimal sensitivity and specificity. If the $10 \mathrm{ng} / \mathrm{ml}$ cutoff had been applied in the patients of our series, it would have yielded high sensitivity (90\%) in the THW group but poor sensitivity (57\%) in the rhTSH group. Recently, Melo et al. (6) have reported a Tg cutoff at $7.2 \mathrm{ng} / \mathrm{ml}$ after rhTSH, a higher threshold than ours $(2.8 \mathrm{ng} / \mathrm{ml})$, which would also have provided low sensitivity $(57 \%)$ in our rhTSH patients. Several explanations are possible. First, the Tg level was measured 3 days after radioiodine treatment in the study by Melo et al. (6) and before treatment in ours. Second, the group of patients prepared with rhTSH was at a higher risk of PRD in the study by Melo et al. (6) than in ours, with a higher proportion of T3/T4 tumors (44 vs 13\%) and of N1 patients (21 vs 11\%). Finally, our patients systematically underwent neck and thorax SPECT/CT in addition to total-body 
scan. Therefore, nonstructural PRD was more likely to be detected in patients with small $(<1 \mathrm{~cm})$ neck lymph nodes and/or microscopic distant metastases as previously shown $(3,9)$. As the Tg cutoff at $2.8 \mathrm{ng} / \mathrm{ml}$ after $\mathrm{rhTSH}$ provided a sensitivity of $86 \%$, it means that $14 \%$ of patients with PRD had a very low stimulated Tg value (i.e. below 2.8). Previous studies have shown that PRD is very unlikely when stimulated Tg levels $(17,18)$, or even unstimulated Tg levels using highly sensitive Tg assays (19), are undetectable. In few patients, however, PRD can be observed in the presence of very low Tg levels after rhTSH $(1.1 \mathrm{ng} / \mathrm{ml}$ in our study). These results are in accordance with previous studies $(17,20)$ and suggest that the value of stimulated Tg should not be the only factor to select patients for radioablation.

\section{Conclusion}

In conclusion, our data clearly showed that the stimulated serum Tg level is related to the burden of persistent/ recurrent tumor and highlighted the impact of the radioiodine preparation modality (rhTSH or THW) on the stimulated serum Tg level at ablation. In practice, therefore, the preparation modality used and the tumor burden should be taken into account when interpreting the stimulated Tg level. For a similar tumor burden, the stimulated serum Tg level after rhTSH stimulation should be expected to be lower than that after THW.

\section{Declaration of interest}

The authors declare that there is no conflict of interest that could be perceived as prejudicing the impartiality of the research reported.

\section{Funding}

This research did not receive any specific grant from any funding agency in the public, commercial or not-for-profit sector.

\section{References}

1 Webb RC, Howard RS, Stojadinovic A, Gaitonde DY, Wallace MK, Ahmed J \& Burch HB. The utility of serum thyroglobulin measurement at the time of remnant ablation for predicting disease-free status in patients with differentiated thyroid cancer: a meta-analysis involving 3947 patients. Journal of Clinical Endocrinology and Metabolism 201297 2754-2763. (doi:10.1210/jc.2012-1533)

2 Toubeau M, Touzery C, Arveux P, Chaplain G, Vaillant G, Berriolo A, Riedinger JM, Boichot C, Cochet A \& Brunotte F. Predictive value for disease progression of serum thyroglobulin levels measured in the postoperative period and after (131)I ablation therapy in patients with differentiated thyroid cancer. Journal of Nuclear Medicine 200445 988-994.
3 Ciappuccini R, Heutte N, Trzepla G, Rame JP, Vaur D, Aide N \& Bardet S. Postablation (131)I scintigraphy with neck and thorax SPECT-CT and stimulated serum thyroglobulin level predict the outcome of patients with differentiated thyroid cancer. European Journal of Endocrinology 2011164 961-969. (doi:10.1530/EJE-11-0156)

4 Haugen BR, Pacini F, Reiners C, Schlumberger M, Ladenson PW, Sherman SI, Cooper DS, Graham KE, Braverman LE, Skarulis MC et al. A comparison of recombinant human thyrotropin and thyroid hormone withdrawal for the detection of thyroid remnant or cancer. Journal of Clinical Endocrinology and Metabolism 199984 3877-3885. (doi:10.1210/jcem.84.11.6094)

5 Heemstra KA, Liu YY, Stokkel M, Kievit J, Corssmit E, Pereira AM, Romijn JA \& Smit JW. Serum thyroglobulin concentrations predict disease-free remission and death in differentiated thyroid carcinoma. Clinical Endocrinology 200766 58-64. (doi:10.1111/j.1365-2265.2006. 02685.x)

6 Melo M, Costa G, Ribeiro C, Carrilho F, Martins MJ, da Rocha AG, Sobrinho-Simoes M, Carvalheiro M \& Soares P. Stimulated thyroglobulin at recombinant human TSH-aided ablation predicts disease-free status one year later. Journal of Clinical Endocrinology and Metabolism 201398 4364-4372. (doi:10.1210/jc.2013-2267)

7 Schlumberger M, Catargi B, Borget I, Deandreis D, Zerdoud S, Bridji B, Bardet S, Leenhardt L, Bastie D, Schvartz C et al. Strategies of radioiodine ablation in patients with low-risk thyroid cancer. New England Journal of Medicine 2012366 1663-1673. (doi:10.1056/ NEJMoa1108586)

8 Mallick U, Harmer C, Yap B, Wadsley J, Clarke S, Moss L, Nicol A, Clark PM, Farnell K, McCready R et al. Ablation with low-dose radioiodine and thyrotropin alfa in thyroid cancer. New England Journal of Medicine 2012366 1674-1685. (doi:10.1056/ NEJMoa1109589)

9 Aide N, Heutte N, Rame JP, Rousseau E, Loiseau C, Henry-Amar M \& Bardet S. Clinical relevance of single-photon emission computed tomography/computed tomography of the neck and thorax in postablation (131)I scintigraphy for thyroid cancer. Journal of Clinical Endocrinology and Metabolism 200994 2075-2084. (doi:10.1210/ jc.2008-2313)

10 Ronga G, Filesi M, Ventroni G, Vestri AR \& Signore A. Value of the first serum thyroglobulin level after total thyroidectomy for the diagnosis of metastases from differentiated thyroid carcinoma. European Journal of Nuclear Medicine 199926 1448-1452. (doi:10.1007/s002590050477)

11 Pelttari H, Valimaki MJ, Loyttyniemi E \& Schalin-Jantti C. Post-ablative serum thyroglobulin is an independent predictor of recurrence in low-risk differentiated thyroid carcinoma: a 16-year follow-up study. European Journal of Endocrinology 2010163 757-763. (doi:10.1530/ EJE-10-0553)

12 Rosario PW, Xavier AC \& Calsolari MR. Value of postoperative thyroglobulin and ultrasonography for the indication of ablation and (131)I activity in patients with thyroid cancer and low risk of recurrence. Thyroid 201121 49-53. (doi:10.1089/thy.2010.0145)

13 Ladenson PW, Braverman LE, Mazzaferri EL, Brucker-Davis F, Cooper DS, Garber JR, Wondisford FE, Davies TF, DeGroot LJ, Daniels GH et al. Comparison of administration of recombinant human thyrotropin with withdrawal of thyroid hormone for radioactive iodine scanning in patients with thyroid carcinoma. New England Journal of Medicine 1997337 888-896. (doi:10.1056/NEJM199709253371304)

14 Torres MS, Ramirez L, Simkin PH, Braverman LE \& Emerson CH. Effect of various doses of recombinant human thyrotropin on the thyroid radioactive iodine uptake and serum levels of thyroid hormones and thyroglobulin in normal subjects. Journal of Clinical Endocrinology and Metabolism 200186 1660-1664. (doi:10.1210/jcem.86.4.7405)

15 Taieb D, Lussato D, Guedj E, Roux F \& Mundler O. Early sequential changes in serum thyroglobulin after radioiodine ablation for thyroid cancer: possible clinical implications for recombinant human thyrotropin-aided therapy. Thyroid 2006 16 177-179. (doi:10.1089/ thy.2006.16.177) 
16 Bachelot A, Cailleux AF, Klain M, Baudin E, Ricard M, Bellon N, Caillou B, Travagli JP \& Schlumberger M. Relationship between tumor burden and serum thyroglobulin level in patients with papillary and follicular thyroid carcinoma. Thyroid 200212 707-711. (doi:10.1089/ 105072502760258686)

17 Nascimento C, Borget I, Al Ghuzlan A, Deandreis D, Chami L, Travagli JP, Hartl D, Lumbroso J, Chougnet C, Lacroix L et al. Persistent disease and recurrence in differentiated thyroid cancer patients with undetectable postoperative stimulated thyroglobulin level. Endocrine-Related Cancer 201118 R29-R40. (doi:10.1677/ERC-10-0292)

18 Rosario PW, Mineiro AF, Prates BS, Silva LC \& Calsolari MR. Postoperative stimulated thyroglobulin of less than $1 \mathrm{ng} / \mathrm{ml}$ as a criterion to spare low-risk patients with papillary thyroid cancer from radioactive iodine ablation. Thyroid 201222 1140-1143. (doi:10.1089/ thy.2012.0190)

19 Giovanella L, Ceriani L, Suriano S, Ghelfo A \& Maffioli M. Thyroglobulin measurement before rhTSH-aided ${ }^{131} \mathrm{I}$ ablation in detecting metastases from differentiated thyroid carcinoma. Clinical Endocrinology 200869 659-663. (doi:10.1111/j.1365-2265.2008.03244.x)

20 Robenshtok E, Grewal RK, Fish S, Sabra M \& Tuttle RM. A low postoperative nonstimulated serum thyroglobulin level does not exclude the presence of radioactive iodine avid metastatic foci in intermediate-risk differentiated thyroid cancer patients. Thyroid 2013 23 436-442. (doi:10.1089/thy.2012.0352)

Received 10 March 2014

Revised version received 13 May 2014

Accepted 27 May 2014 